\title{
Low Carbon Economy Development: China's Road and Policy Choice
}

\author{
Xiangsheng Dou ${ }^{1,2}$ \\ ${ }^{1}$ School of Public Administration, Southwest Jiaotong University, Chengdu, China \\ ${ }^{2}$ Center for International Economic Research, Southwest Jiaotong University, Chengdu, China \\ Correspondence: Xiangsheng Dou, School of Public Administration, Southwest Jiaotong University, Jinniu, \\ Chengdu, 610031, Sichuan, China. Tel: 86-028-8763-4337. E-mail: douxiangsheng@tsinghua.org.cn
}

Received: March 10, 2013 Accepted: April 1, 2013 Online Published: July 3, 2013

doi:10.5539/jms.v3n3p95 URL: http://dx.doi.org/10.5539/jms.v3n3p95

\begin{abstract}
The choice of low carbon economy development road is directly related to whether the low carbon economy development goal can be achieved smoothly and effectively, while its choice theory and economic contents are very rich. Therefore, it is necessary to explore it from a broader perspective. Only by doing so, can we overall understand and grasp its profound essences of theory and economic contents, so as to outline a clear roadmap for low carbon economy development and to provide scientific theory foundations for the policy formulation and implementation. This paper, from different perspectives including the development methods, tactics, path, power, means, priorities and so forth, comprehensively and systematically demonstrates the low carbon economy development road and the economic contents of its choice. The research reveals that, under the particular context at this stage, China's low carbon economy development must take such a development road, for example, the combination of the government-led and the market-oriented operation, the combination of the overall gradual and the partial rapid development, the combination of the balanced development in a long term and the unbalanced development in a short term, the combination of the exogenous and the endogenous development, the dual governance of the carbon source and the carbon sink, as well as the industry and the energy low-carbonization development based on low carbon technology innovation.
\end{abstract}

Keywords: low carbon economy, low carbon economy development road, low carbon economy policy, industrial low-carbonization development, energy low-carbonization development

\section{Introduction}

As a new economy, low carbon economy in the new round of the world economy development will play an increasingly important role. Because it involves not only such a simple economic problem as the energy conservation and consumption reduction and emission cut and addressing the climate change, more importantly it will fundamentally affect and change the production way and the lifestyle of people, which will create the higher standards of living, the better quality of life and the more opportunities for development for people (the British Government, 2003). Therefore, it is a basis and an inevitable requirement to achieve the sustainable development of socio-economy, which represents the direction and trend of future socio-economic development and will become an important new driving force for socio-economic development. Especially in the context of growing economic globalization, low carbon economy development is not just an economic and technical issue, but it is also a political issue, and only the countries that have an advantage in low carbon economy game may win more room for development and more development opportunities in the future international competition. Therefore, low carbon economy is sweeping the globe in the ascendant trend, and has become the new trends of leading the world economy development and the new engine of promoting the world economy development at the current stage (Junfeng L., LingJuan M., 2008).

China is a developing country, and at this stage the economic structure and the level of economic development in China is not still very developed, which is currently being at the stage of economic transition. How to speed up economic structure transformation and to promote the economy forward to higher level, has become the focus of China's economic development strategy. The main factors restricting China's economic development 
are relatively backward industrial structure, obviously insufficient technological innovation capability, and seriously extensive economic growth phenomenon with a large number of resource consumption to sustain the growth, which not only results in the serious problem of the inefficient use of resources and energy, but also aggravates the contradictions of the energy shortage and the environmental pollution. Therefore, it is necessary vigorously to promote the energy saving and the consumption reduction and the emission cut, actively to protect the resources and the environment, and effectively to protect the energy security and the ecological sustainability (Xiangsheng, D. et al., 2013). This needs completely away from the traditional pattern of economic development, and to take the road of low carbon economy development to fundamentally solve the structural contradictions in socio-economic development.

Since the idea of the "soft energy path" was proposed by Amory Lovins (1977) in the 1970s, the issue of the climate change caused by greenhouse gas emissions has been increasingly followed with interest. At the same time, the belief and ideology of low carbon society action to address climate change is gradually taking shape, too. International community has recognized that to develop low carbon economy is inevitable choice for every country in the world. However, how to realize the low-carbonization development of economy as short time as possible to ensure that in the next 100 years the increase of average global temperature is at no higher $2^{\circ} \mathrm{C}$ than the pre-industrial period, has become an important problem that all countries in the world are trying to resolve (Hourcade J.C., Crassous R., 2008). From a practical point of view, the signing of "the United Nations Framework Convention on Climate"(1992) and "the Kyoto Protocol"(1997) taking the reduction of greenhouse gas emissions as the core marks that, the international community has successfully stridden forward towards the road of low carbon economy development. Especially after the concept of "low carbon economy" was clearly put forward firstly by the British Government in its "the 2003 Energy White Paper", the international community has taken the low carbon economy for the action objectives of future development. Following "the Kyoto Protocol"(1997), a series of the United Nations climate change conferences such as "the Bali Island Roadmap"(2007), "the Copenhagen Conference"(2009), "the Durban Conference" (2011), "the Tel Aviv Conference" (2012) and so forth, further clarify the ideology and standpoint of promoting the revolutionary transformation of the world economy from the industrial civilization of high-carbon economy to the eco-civilization of low-carbon economy, which has formally established the road of the world economy development to a low carbon economy (CCLCERIRUC, 2010).

With the introduction of low carbon economy concept and its practical development, the literatures that research and probe the road of low carbon economy development in academic circles are growing. However, most literatures are focusing on exploring the reality and long-term development of low carbon economy. For example, some scholars addressed the modeling study for the future long-term development of low carbon economy. By the analysis on the problems such as the scale and timing of the development of low carbon technologies, the carbon pricing and the implementation of relevant incentive policies, the low carbon cost evaluation and so forth, they concluded that the actions and goals of low carbon socio-economy are not a utopian fantasy. As long as the policies and measures are properly made, low carbon economy will certainly be realized (Neil Strachan, 2008; Hourcade J. C., Rassous R., 2008). UWE Remme and Markus Blesl (2008) prospected for the realization issue of low carbon socio-economy from a global point of view, and used the ETSAP-TIAM model to analyze the low carbon society planning, gaining similar conclusions as Neil Strachan (2008) et al. From the existing research literatures, a lot of research literatures have only explored the direction, road and conditions of low carbon economy development, and still have not drawn consistent conclusions from the studies.

The research literatures about the road of low carbon economy development for China, in recent years, are increasing, too. From the foreign research to view, some literatures explored the energy use and the carbon emissions in China from the aspect of market reform and structural change, and put forward the way of achieving the targets of carbon emission reduction (Xiangsheng, D. et al., 2013). For example, through the structural reforms to reduce the energy consumption and the intensity of carbon emissions, by the change in the relative price of energy to improve the energy structure, with the adjustment of economic scales to change the level of outputs and so forth (Karen Fisher-Vanden, 2003). However, what more research literatures explore is the issues such as the system of carbon trading, the carbon pricing and its interrelated policy design and so forth, and the literatures that specially study the road of low carbon economy development for China are relatively fewer (Ellerman A. D., 2002). In contrast, the domestic research literatures on the road of low carbon economy development are relatively more, and most of research literatures concluded that the possible roads to promote the low carbon economy development for China were to adjust the energy structure, improve the energy 
efficiency, adjust the industrial structure, curb the extravagant consumption and play the carbon sink potentials (Zhijun F., 2009; Guiyang Z., 2005; Jiahua, P., 2009; Jianqiang B. et al., 2008).

In fact, because China's economy at this stage is undergoing a structural reform and during the transition period, so the problems and contradictions related are much more. In this case, only to select a correct development road, can China smoothly and effectively promote low carbon economy development. However, the road of low carbon economy development is in turn related to the development pattern, the development strategies, the development path, the driving force for development, the development means, the development priorities and the other related issues of low carbon economy, and it is just these development factors to determine the road of low carbon economy development together. Only clearly to demonstrate those problems, can the profound essence of theoretical and economic connotation of low carbon economy development road be really understood and grasped.

However, the current research literatures in this respect are less and the studies were not thorough enough. Therefore, it is necessary to explore the issue of low carbon economy development road from a broader perspective. Only by doing so, can we overall understand and grasp its profound essences of theory and economic contents, so as to outline a clear roadmap for low carbon economy development and to provide scientific theory foundations for the policy formulation and implementation. This paper will from different perspectives including the development methods, tactics, path, power, means, priorities and so forth, comprehensively and systematically demonstrate the low carbon economy development road and the economic contents of its choice to provide theory and policy basis for China's low carbon economy development.

The remainder of this paper is organized as follows. The second part will demonstrate that, at this stage, China must take the road of the combination of the government-led and the market-oriented operation development to promote low carbon economy development from the perspective of development. The third part will explore the development law that China must take the road of the combination of the overall gradual and the partial rapid development in a long time from the perspective of strategy. The fourth part will analyze the issue that China must choose the road of the combination of the balanced development in a long term and the unbalanced development in a short term from the perspective of development path. In the fifth part, it will be argued that it is necessary for China to take the road of the combination of the exogenous and the endogenous development from the perspective of the driving force of development. The sixth part will talk the topic that China must take the road of the dual governance of the carbon source and the carbon sink from the perspective of development means. In the eighth part, the problem of low-carbonization development road of industries in China will be discussed from the perspective of technological innovation. In the ninth part, the problem of low-carbonization development road of energy in China will be addressed from the perspective of technological innovation to discuss. Final part is a conclusive review.

\section{The Government-Led and the Market-Oriented Operation}

Because low carbon economy is a new economy from the fundamental changes of traditional economy, it involves the change of the mechanism and pattern of economic operation as well as the change of corresponding economic and social system, which needs properly handle the relations between the government's role and the function of market. Especially in the case that the current market system is not very perfect, one of the most key factors that affect low carbon economy development in China is the proper policies and measures of the government. Therefore, low carbon economy development in China must take the road of the combination of the government-led and the market-oriented operation. In other words, under the current conditions, low carbon economy development in China must under the guidance and promotion of the government be carried out. At the same time, in the specific development process, it is necessary to fully play the role of market mechanism, which uses the market-based instruments to guide and encourage micro-economic entities to actively take a low carbon economy action. It is another necessary condition for low carbon economy development.

Under modern production conditions, the government and its economic policies play a crucial role on safeguarding the orderly operation of economy. As a new economy, low carbon economy development is inseparable from the role of the government. This is because low carbon economy is the trend and strategic choices of futuristic economy development and has a foundation and key role on the future development and prosperity of a country. At the same time, it is related to the various aspects of socio-economy, and thus it is a socio-economic systematic engineering. This needs the government from the aspect of overall situation to make a scientific and systematic strategy planning for the future development of low carbon economy, and on this basis further to draw up the goal, the pattern, and the technology roadmap of low carbon economy transition and 
to take the corresponding policy measures to realize it. Only under the correct guidance of the scientific strategy planning and the related regulations and policies, it is possible to promote the healthy development of low carbon economy. In particular, China's market and its related organizational systems at this stage are still not perfect, and in some economic areas the market mechanism is still difficult to play a full role. In this case, it is particularly important to play the role of the guidance and support of the government. If there is no the guidance and support of the government, low carbon economy development is practically impossible. From the practical aspect to view, all major countries in the world (including the developed and the developing countries) have almost worked out the planning of low carbon economy action and their own medium-and-long term targets of greenhouse gas emission reduction. Some countries such as the Britain, the Japan and the United States etc., have formulated more comprehensive laws and regulations and support policies around the energy conservation and emission reduction, the renewable resource and energy use, the new energy development, the low carbon industrial development and so forth, which lays out a clear roadmap for the future low carbon economy development (Jijun X. et al., 2010). China should learn the experience of low carbon economy development from these countries to make a scientific planning for the future development of low carbon economy in China.

Low carbon economy development is built on the basis of technological innovation. If there is no the low carbon technological innovation, it is impossible to make a success for low carbon economy development. However, only under the vigorous promotion and support of the government, can the low carbon technological innovation be completed. The low carbon technologies include the energy saving and emission reduction technologies, the renewable energy and new energy technologies, the carbon capture and sequestration and utilization technologies, the eco-industrial engineering technologies (including the recycling and use technologies of renewable resources, etc.), the ecological agriculture technologies and so forth. These technologies are almost covering all aspects of production and life of people (Jijun X., et al., 2010; Yong J., Jakob de Swaan Arons, 2009). For some of basis and key technologies in low carbon technologies, due to the higher requirements of $\mathrm{R} \& \mathrm{D}$ conditions and the bigger R\&D risks, it is necessary under the direct promotion and the key subsidization of the government that a significant innovation is possible to be obtained. Even for some of applied low carbon technologies, just simply relying on the firm's own innovation are still difficultly developed and applied, for the current energy technologies more consider their economic benefits. However, the low carbon energy technologies should consider not only the economic benefits of the technologies, but also the ecological benefits of the technologies. Therefore, the low carbon energy technologies are not only more complex in the technology development and application, but also can result in the rising of energy production costs, which will greatly affect the enthusiasm of the innovation and application of new energy technologies for the firms. In this case, it needs the government to give some essential subsidizations and supports for the energy technology innovation of firms. In a word, no matter what the research and development of low carbon technologies or its application, all are inseparable from the promotion and support of the government, and it is not able just to rely on market mechanisms. At present, all countries in the world actively take various policy measures to promote and support the R\&D and innovation of low carbon technologies to seize the high ground of the new technologies. China should learn the experiences from other countries, and full play the role of the government on the low carbon technological innovation, so as to obtain a dominant position in certain areas of low carbon technologies.

Low carbon economy development needs also appropriate organizational service system to support, and these must be provided and supported by the government. Under the conditions of market economy, low carbon economy development heavily relies on market mechanisms, and this needs to establish an efficient and diversification market system of carbon emission right trading and a sound market organization and service system to facilitate the carbon trading (Yao W., 2010). Obviously, the market participants can not resolve this contradiction by themselves and it is necessary by the government to resolve it. Another key factor for low carbon economy development is enough financial support. Whether it is the low carbon technological innovation, the implementation of energy saving and emission reduction project and the new energy investment, or the trading of carbon emission rights, all need a lot of money. This needs the government to formulate relevant policies and measures to promote financial innovation, quickly to establish and perfect the carbon credit system and market-based carbon financing mechanism for the services of low carbon economy development, and actively to encourage the enterprises and financial institutions to provide funds for low carbon economy development. In addition, for the investment and financing of low carbon development such as major low carbon technology innovation and its industrialization, because the investment risks are relatively large, so the private and social capitals do not want to intervene in it. This needs the state and local governments by way of establishing carbon funds directly to provide funds. It is thereby obvious that low carbon economy development 
needs the government to provide a perfect market, necessary funds and other services. And only if these aspects are satisfied, low carbon economy development is possible. However, these problems can not fully be resolved by the micro-economic entities and the market themselves.

Different from the traditional economy taking socio-economic welfare maximization as a goal, low carbon economy needs not only to achieve the socio-economic welfare maximization, but also to maintain the ecological balance to achieve the harmonious development between the economy, the society and the nature. This is an essential difference between the low carbon economy and the traditional economy. Generally speaking, the market mechanism is favorable to stimulating the dynamism and vitality of economic development to efficiently promote economic development. However, the market mechanism is difficult to play a role on the social welfare and the ecological balance, for the social welfare is related to both the total economic growth and the equitable distribution of society, and the ecological balance is related to the balanced and harmonious development between the socio-economic systems and the natural ecosystems. In these aspects, the market mechanism is difficult to play a role. Especially on the ecological balance, if only to play the role of the market mechanism, it is not only unable to maintain ecological balance, but more importantly it can also take the ecological environment worse. This is because the economic activities of people are built on the basis of the natural world, yet the natural world has certain physical limits and specific bearable capacities for development. If people indefinitely make a predatory development on the natural material world, it will seriously undermine the balance of natural ecosystems, and make the natural ecosystems to lose the capacity for sustainable development (Bartelmus P., 2008). However, in the role of market mechanism, all the economic activities of people are to maximize the economic benefits as a goal. With the continuous growth of material wealth, people extort from the natural material world more and more, too. If allowed to grow unlimitedly, it may eventually cause an over-exploitation on the natural material world, and further result in the serious consequences of the imbalance of natural ecosystems and the ecological environment deterioration. This is a typical example of market failure. Therefore, in the field of ecological environment, the market mechanism is powerless to do all things, so it is necessary to full play the role of the government.

Of course, under the government's guide to promote low carbon economy development does not mean that low carbon economy development needs not play the role of market mechanism. On the contrary, in the low carbon economy development, the basic role of market mechanisms on resource allocation must be brought into play, or else low carbon economy can not obtain a development, as under the conditions of market economy the role of the government is established on the basis of the market mechanism, and the role of the government is to protect the market mechanism to play a better role rather than to replace the role of the market mechanism. Although in the low carbon economy development the market mechanism can not automatically play a role on maintaining ecological balance, the government can take the relevant regulations and policies and the economic incentives to integrate the target of ecological balance to the target of economic interests, and thereby by the role of the market mechanism achieve the harmonious development between the economy and the ecology. For example, by the carbon tax (or the environmental taxes) or the carbon subsidies to encourage the enterprises to carry out the energy saving and emission reduction, not only may get the purpose of the energy saving and emission reduction, but also may ensure the maximization of enterprise interests, which can play the effect that one stone hits two birds. In fact, the Coase theorem has told us that to use market mechanism to solve environmental problems can be a more efficient manner. From the process of low carbon economy development to view, the low carbon economy development needs the joint efforts of the government, the businesses and the individuals. Among them, the businesses and the individuals are in a basic position, and the role of the government is through the businesses and the individuals to play. Because the goals and behaviors of the businesses and the individuals are a pluralistic, only fully to use the market mechanism, can those wide range conflicts and the relations of economic interests be effectively solved, and this is just point that the market mechanism has an advantage over the role of the government. In turn, only fully to play the role of market mechanism in low carbon economy, can the low carbon economy development be effectively promoted. Therefore, it is necessary correctly to handle the relationship between the government-led and the market-oriented operation, that is, not only fully to play the role of the government, but also fully to take advantage of the market mechanism, so as more effectively to promote low carbon economy development. In other words, in the pattern and strategy of development, to take the road of the combination of the government-led and the market-oriented operation will be an inevitable requirement and a practical way for effectively promoting low carbon economy development.

\section{The Overall Gradual Development and the Partial Rapid Development}

The gradual development emphasizes the balanced, orderly and gradual progress of development. However, the 
rapid development takes the leaps and bounds and the rushing and surpassing development as the basic characteristics. Obviously, the path of gradual development is gentle, continuous and orderly, and it is conducive to realizing the harmonious or optimal growth of economy, but it is bound to paying the time costs of development, for it needs a fairly long time to eventually achieve the goal of economic development. As for the rapid development, because the path of rapid development is leap, discontinuous and chaotic, so it can take an imposed development in a lower level or in a higher level, and thereby in a short term it is difficult to achieve the harmonious or optimal growth of economy, but it can rapidly achieve the goal of economic development within a short period of time. Therefore, the gradual development and the rapid development have their own advantages and disadvantages, respectively. Under different development environments and conditions, the function and role what they play is not the same, too (Xiangsheng, D., 2002).

As for low carbon economy development is concerned, because China's economy at this stage is essentially high carbon economy that is established on the basis of fossil fuels characterized with high inputs, high consumptions, high emissions and high pollutions, so the major task of low carbon economy development is how to promote the development pattern shift from traditional high carbon economy to new low carbon economy. To this end, China's low carbon economy development should take the road of better and more economical development based on the China's reality. To get this request, from the aspects of China's realities and the nature of low carbon economy development to view, to take the low carbon economy development road of the combination of the overall gradual and the partial rapid development pattern, seems be an ideal road for China's low carbon economy development at this stage.

From the aspects of development strategy and overall development to view, the low carbon economy development in China should take a gradual development road, which is determined by the realistic situation of China's economic development at this stage. Actual situation in China at this stage is that, on the one hand, the operation of economy as a whole is based on high carbon economy that mainly consumes the fossil energy, but this situation is very difficult to be completely changed in the near future for a long time. On the other hand, at this stage the industrialization in China has not still been achieved, and China's economy is still in the process of transforming from extensive growth to intensive growth. Furthermore, in certain sectors and industries the extensive growth phenomenon is still quite prominent, and the carbon emission intensity of GDP per unit is significantly higher than that of the world's average, which in turn exacerbates the difficulty of the transition from high carbon economy to low carbon economy. In this case, to try to achieve the task of low carbon economy development in a short period of time is unrealistic, for one of the most important marks to measure the effectiveness of low carbon economy development is the reduction of carbon emission intensity of GDP per unit. Obviously, if in a short time significantly to reduce the carbon emissions intensity of GDP per unit, it will undoubtedly affect the speed of economic development. However, low carbon economy development must be established on the basis of economic development. If there is no economic development, then low carbon economy development will lose its basis and condition.

In fact, the purpose to promote low carbon economy development is better to promote economic development. Although in a long run the low carbon economy development is the source of power and the necessary and sufficient conditions to achieve sustainable socio-economic development, in a short run there is the possibility of conflicts between the goal of low carbon economy development and the goal of real socio-economic development. Because low carbon economy development needs innovate and optimize the existing economic structure and economic operation pattern to virtually eliminate irrational factors restricting the vitality and efficiency of economic development and to create the conditions for sustainable socio-economic development, but this process of economic transformation will inevitably lead to the changes in the existing economic order and pattern of economic interests, so to a certain extent this will affect and change the real process of economic development. Therefore, overall speaking, low carbon economy development in China can only take the gradual road of development. Only by doing so, it is possible under the condition of real economic development to vigorously promote the low carbon economy development, so as to form a win-win situation of sustainable development of mutual coordination between low carbon economy development and socio-economic development.

However, overall gradual development does not preclude partial rapid development. From the development strategy and specific development circumstance to view, for certain regions or industries it is possible to take a leap and rapid development road, and this not only helps to accelerate the development of partial low carbon economy, but also helps by the partial carbon economy development to boost the development of overall low carbon economy. This is because China is a great developing country, and the structure and function level of 
socio-economic systems in different regions and industries has obvious differences, resulting in the differences of the basis and environmental conditions of low carbon economy development, too. In this case, it is necessary differentially to promote low carbon economy development according to the specific conditions of different regions and industries. For some relatively better regions and industries, it is possible to break the routine and to practice the development of the leaps and bounds, so as at a higher standard and a higher level to promote low carbon economy development, and thereby to accelerate the achievement of low carbon economy development goals. However, for a number of relatively poorer regions and industries in the development conditions, it is necessary gradually and orderly to promote low carbon economy development according to the actual condition, and this will help to reduce or eliminate a variety of social and economic contradictions probably caused by low carbon economy development.

Of course, in the process of implementing the partial rapid development many problems may be induced, too. Different from the overall gradual development, one of the most important issues what the partial rapid development faces is that, what region and what industry have actually the rapid development conditions. Obviously, how to scientifically and rationally select them has many uncertainties and difficulties. Furthermore, even if it is possible to scientifically and rationally select the regions and industries that may take a rapid development, yet how to take the discriminatory policies is a practical problem, again. Because these regions and industries with rapid development will inevitably require a better development policy environment and a better service and support system, all these need the government in the process of drafting development planning and policy design differently to treat the appropriate regions and industries, and focally to take supports and financial assistances, so as to accelerate the low carbon economy development in these regions and industries. However, these differentiated policies further involve the problem of equity between different regions and industries. In addition, to implement the differentiated development of different regions and industries of low carbon economy is only a strategic choice to adapt to the specific initial underdeveloped stage of low carbon economy development, and the purpose is through the differentiated development to accelerate the development process of low carbon economy. When low carbon economy development reaches a certain level, it is necessary immediately to realize the transition from differentiated development to synchronous development to promote low carbon economy to enter a stage of comprehensive development. However, what long should actually be this transitional period? Whether or not can achieve a smooth transition between the two? These problems are worth considering.

In a word, under the current socio-economic conditions of China at this stage, from the strategy and nature of low carbon economy development to view, the low carbon economy development in China may take the development road of the combination of the overall gradual development and the partial rapid development. This is an ideal way to effectively promote low carbon economy development under the current specific socio-economic conditions. Of course, in specific practice it is necessary to correctly handle the relationship between the overall gradual development and the partial rapid development. Generally speaking, the overall gradual development is the principles and the premises, and it is the basis that overall ensure orderly and healthy development of low carbon economy. Only on this premise and foundation, can the rapid development according to the actual situation be partially practiced. At the same time, the partial rapid development can not completely keep pace with the overall gradual development, and it should have relative independence and significant surpassing feature, by the development of leaps and bounds to highlight its demonstrative and guiding role to promote the comprehensive development of low carbon economy, which is one of main purposes to practice the partial rapid development.

\section{The Balanced Development and the Unbalanced Development}

From the aspects of development path and pattern to view, China's low carbon economy development can go either the road of balanced development or the road of unbalanced development. However, because they are two entirely different roads of development, so the development effects what they actually take are not the same, too. The balanced development is based on the general equilibrium theory and the principle of optimal allocation of resources, which is characterized with the uniqueness and optimality of development path. Contrary to the balanced development, the unbalanced development is based on the multiple dynamic equilibrium theory of non-steady-state and the second-best resource allocation principle, which is characterized with the multidimensional nature and the second-best of development path (Xiangsheng D., 2002). Clearly, from the practical point of view, every of the balanced development and the unbalanced development has their own advantage, respectively. The result of balanced development is ideal, but because of the uniqueness and the optimality of its development path, so the conditions of its implementation are more stringent and the difficulty 
of the actual operation is greater, and thereby in practice it is often difficult to be implemented effectively. The result of uneven development is not satisfactory and at best the second-best, but because of the multidimensional nature and the second-best of its development path, so in practice it tends to be easier implemented. Therefore, it is necessary on the basis of the actual conditions and according to the different situations to select the different road of low carbon economy development.

In a long run, the low carbon economy development in China must go the road of balanced development. Because from whole country to see, the socio-economic system is an open system formed by the different regional subsystems and the different industrial subsystems, and there are interrelated and close inseparability between different regions and between different industries, this decides that it is necessary to comprehensively promote the low carbon economy development within the scope of whole society and all regions and industries. Only by doing so, can the goals of low carbon economy development be realized. Especially, in the case that the initial conditions of low carbon economy development are relatively backward, to take the road of balanced development may provide the basic conditions for the low carbon economy development of various regions and industries, which can get inherent and external development benefits, effectively to avoid the phenomenon of the partial excess or shortage development abilities that can happen from the unbalanced development (Xiangsheng D., 2002). Of course, to take the road of the balanced development does not mean that all regions and industries make the development hand in hand. Because the marginal carbon emission rate and the marginal carbon treatment cost caused by the socio-economic activities of different regions and industries are not the same, so the low carbon economy development in different regions and industries at least in the aggregate volume may be inconsistent. However, this does not exclude the consistency of the ultimate effects of low carbon economy development of all regions and industries. In fact, the reason that stresses the importance of taking the road of the balanced development in a long run is to ensure that the low carbon economy development in all regions and industries will be eventually realized.

However, due to the backwardness of the initial conditions of real low carbon economy development, the development differences in different regions and industries are very great. Therefore, to take the road of unbalance development in a short term may be more realistic. Because the marginal carbon emission rate and the marginal cost of carbon treatment in different regions and industries are not the same, for some of the regions and industries that have a higher marginal carbon emission rate and relatively lower marginal cost of carbon emission treatment, it may be given priority to promote low carbon economy development, or in a certain period of time to concentrate their efforts to promote the low carbon economy development in these regions and industries. Furthermore, because there are strong linkage effects, spillover effects and learning effects between the different regions and industries, so the priority development of low carbon economy in these regions and industries can effectively drive the low carbon economy development of other regions and industries. As long as the measures are proper, after a long time effort, the balanced development of low carbon economy in all regions and industries will be ultimately achieved. In fact, under the circumstances that the real economic resources are limited, in a short term to take the road of unbalanced development and through a short-term imbalanced development finally to achieve the optimal development, is a feasible way that any economic development must pass through under the conditions of undeveloped economies, and low carbon economy development must also follow this law of development. From a practical point of view, at present most of the countries and regions that the low carbon economy develops very well, for example, the Britain, the Japan, the United States and so forth, are all going the unbalanced development road that concentrates a strength and gives a priority to promote the low carbon economy development of certain regions and industries. Of course, the specific way of the development taken by different countries and regions can be not the same.

Due to the non-uniqueness and non-optimality of the unbalanced development road, thus compared to the balanced development, the issues what the unbalanced development involves will be more complex. From the development process to view, the basic characteristic of the unbalanced development is partially to advance step by step, and it is through the gradient advance to achieve the transition of low carbon economy development from a short-term imbalance to a long-term balance. From the specific path-dependence to view, the unbalanced development has two different forms of direct gradient advance and inverse gradient advance. The core of the direct gradient advance is that it emphasizes low carbon economy development in accordance with the descending order of advance, that is, according to the order from the high to the low to push forward. For example, firstly the focus on the regions and industries of the intensity of big carbon emissions and the heavy pollution to take a low carbon action, and then gradually extended to all regions and industries. However, the inverse gradient advance is contrary, and it emphasizes low carbon economy development in accordance with 
the ascending order of advance, that is, according to the order from the low to the high to push forward. For example, firstly the focus on the regions and industries that the intensity of carbon emissions is relatively small and the pollution is less serious to take a low carbon action, after gaining an experience, again to take the carbon emissions of these regions and industries as a common standard to gradually apply the emission standard to all regions and industries.

Obviously, both the direct gradient advance and the inverse gradient advance have their own advantages and disadvantages, respectively. The direct gradient advance has the features of focal point breakthrough from the hard to the easy, and its demonstration effect and influence is relatively larger, but it may produce the problems of the policy mismatch and the high marginal carbon governance costs. Especially at the early stage of low carbon economy development, due to the lack of practical experience, it is more likely to cause these contradictions. As for the inverse gradient advance, as it has the feature of the "try and error" from the easy to the difficult, which helps to reduce the policy mismatch and the high marginal carbon governance costs, but its demonstration effects and influences are relatively weak. Therefore, in the actual development, it is necessary to consider the realistic conditions selectively to use them. In fact, due to the complexity of socio-economic system, in some cases it is difficult to judge the pros and cons of both. In particular, the socio-economic system is always in an unceasingly change and evolution, and in this case it is necessary to combine the actual condition to make a right choice. From whole or greater socio-economic system to view, it is likely to organically combine both for use according to the actual condition of different subsystems, so as to full play the complementary effects of both.

From the aspect of the propulsion mechanism of the unbalanced development to view, whatever way of gradient advance is selected, all need to select the appropriate source of start-up and build a sustainable propulsion mechanism. In general senses, the specific propulsion mechanism may take two different forms of the inherent innovation-typed promotion and the external participation-typed promotion. The inherent innovation-typed promotion is mainly by the overall low carbon technology and system innovation and thereby for microeconomic entities to provide the basic development conditions to promote low carbon economy development in different regions and industries. As this propulsion way is established on the basis of the innovation of low carbon technology and system, so its source of power comes from the internal force of microeconomic entities. For the microeconomic entities, it has the unceasingly inner driving force. As long as the government creates a suitable environmental condition for the innovation of low carbon technologies and systems, for example, to provide a basic innovation platform of low carbon technologies and systems and the necessary incentives for microeconomic entities, then it can guide the microeconomic entities consciously to promote low carbon economy development. Different from the intrinsic innovative propulsion, the external participatory propulsion is mainly through the laws and regulations and a variety of economic incentives or administrative compulsory measures to promote the low carbon economy development in different regions and industries. As this propulsion way is not necessarily built on the basis of the innovation of low carbon technologies and systems, so its source of power comes from the external force of microeconomic entities. For the microeconomic entities, it has not a continuous internal impetus force. Of course, after a period of imposed promotion, the related microeconomic entities is bound to make an adaptive response, and once into this phase, then the microeconomic entities will according to its inherent path consciously to promote low carbon economy development.

From the above analysis we can find that, although in a short run the choice of the unbalanced development road of low carbon economy development seems to be inevitable, yet in the specific implementation many problems will be still encountered. How to select an appropriate advancing road and effective advancing mechanism to promote the low carbon economy development is directly related to the success or the failure of low carbon economy development. From a practical point of view, although the specific propulsion mechanism of different countries and regions has great differences, they have all made good results. Therefore, it is necessary on the basis of the characteristics and conditions of low carbon economy development of different regions and industries, flexibly to take appropriate propulsion mechanism to take best development effects.

\section{The Combination of the Exogenous Development and the Endogenous Development}

How to promote low carbon economy development is one of the most important issues what the circles of theory and practice concern, for it is directly related to the quality and effectiveness of low carbon economy development, and even directly related to the success or the failure of low carbon economy development. From the dynamics of development to view, low carbon economy development can take two different ways of the 
exogenous and the endogenous development. The essence of the exogenous development is that low carbon economy development in a specific socio-economic system is mainly promoted by the internal forces of specific socio-economic system such as the endogenous resources, capital, and technology and so forth. However, the exogenous development mainly depends on the external forces of specific socio-economic system such as the exogenous resources, capital, technology, institution and others to promote (Xiangsheng D., 2002). Obviously, the power source of the two different ways is completely different, and thereby their quality and effectiveness of development can not be the same, too. Of course, the development conditions what they need have differences, too. This needs under different conditions to take different development ways to more effectively promote low carbon economy development.

Because low carbon economy is a new economy that is different from the traditional economy, its development inevitably needs certain basic conditions such as the resources, capital, technology, system and others. For an undeveloped socio-economy, as the cumulative factors of initial economic development are limited, which the power and vitality of its own development is originally innate deficiency, so it is more short of the necessary conditions of low carbon economy development. Even in a well-developed socio-economy, at the initial stage of low carbon economy development, because the original development conditions are not able to adapt and meet the new requirements of low carbon economy development, so it does not fully possess the conditions of low carbon economy development, too. In this case, it is necessary from the outside of specific socio-economic system to pour into certain development factors what low carbon economy development needs, for example, the resources, the capitals, the technologies, the systems and so forth, so as timely to start and continuously to promote low carbon economy development. This means that, for the underdeveloped socio-economy or at the initial stage of low carbon economy development, in order to overcome the lack of the initial development conditions of low carbon economy, it is generally necessary to take an exogenous development way to promote low carbon economy development. Otherwise, if solely to rely on its own strength of socio-economic system, then low carbon economy is actually difficult to be developed. Even if it can be developed, this will also be going through a long process to be finally completed, which is determined by the inherent contradictions of specific socio-economic system.

Of course, although the exogenous development of low carbon economy stresses to inject certain development factors from the outside of specific socio-economic system to promote low carbon economy development, this does not mean that low carbon economy development may separate oneself from its own development environments and change law of a specific socio-economic system. On the contrary, whether the exogenous development of low carbon economy can or not take a success depends largely on whether the development factors injected into from the outside of the specific socio-economic system can be organically integrated into the internal operation mechanism of the specific socio-economic system. If a good integration between both is made, it helps undoubtedly to rapidly promote the low carbon economy development of specific socio-economic system. However, if the integration of both is not good, it not only is not conducive to low carbon economy development, but also may lead to the disorder of the original socio-economic operation mechanism of the specific socio-economic system, affecting the normal operation of the specific socio-economic system. This is because the socio-economic system has the structural features of the self-coupling as well as the dissipation. However, compared to traditional high carbon economy, low carbon economy has a certain degree of heterogeneity. Therefore, when certain low carbon economy development factors are injected into the existing socio-economic system, at least at the early stage of low carbon economy development, new socio-economic systems need a transitional process of self-coupling, and this process may dissipate certain energy. However, once this process is completed, the new socio-economic system will run and develop consciously along the inherent path of low carbon economy development. In other words, in the exogenous development the low carbon economy development is bound to experience a continuous adaptive process of development from the lower to the higher, and this is an evolutionary replacement process (Yong J., Jakob de Swaan Arons, 2009). Only to complete this evolutionary replacement process, can the low carbon economy enter the track of normal development.

Then, how can we from the outside of specific socio-economic system inject the development factors what low carbon economy development needs? This is a very challenging problem. For a specific socio-economic system, the channels that inject the development factors of low carbon economy development from the outside of specific socio-economic system mainly have the government, other socio-economic system and foreign socio-economic organization. Among them, the government's role is particularly important. Especially on the key low carbon technological innovation, low carbon system innovation, low carbon credit system construction, 
low carbon market system construction and so forth, only the government has the appropriate support conditions, and this role of the government can not be replaced by any other socio-economic entities. However, the capacity of the government, after all, is limited. Even in the developed country, the government can only provide the basic necessary conditions for low carbon economy development. Therefore, it is still necessary actively to create necessary conditions, and to introduce the development factors what low carbon economy development needs from domestic other socio-economic sub-systems and the foreign. Furthermore, generally the government's supports for low carbon economy development of specific socio-economic systems are often with the nature of subsidies or aids. However, different from the role of the government, whether the domestic other socio-economic sub-systems and the foreign inject the factors of low carbon economy development into a specific socio-economic system and how much to inject them, depends on whether they can make the expected benefits from it. In other words, this is a process of fully market-oriented operation, which needs appropriate incentives to promote it, and the specific incentives is again related to the two levels of the relevant incentive mechanism of the government's policies and the self-interest incentive mechanism of specific socio-economic system. Therefore, it is obvious that, the exogenous development of low carbon economy has in practice a certain degree of uncertainty.

However, just as any other forms of socio-economic development, the low carbon economy development of a specific socio-economic system will ultimately rely on its own inner strengths to push mainly, and can not always rely on external forces. Therefore, when the low carbon economy development of a specific socio-economic system reaches a certain level, it is necessary timely to drive the transition from the exogenous development to the endogenous development. This is because, on the one hand, for any socio-economic systems, its exogenous development factors are always limited, and can not be infinitely injected from the externals. On the other hand, when the low carbon economy development of a specific socio-economic system reaches a certain level, the internals of this system have inevitably an inherent development mechanism and strong strengths to drive and decide low carbon economy development. And once this inner mechanism of low carbon economy development is formed, then it will continue to develop itself according to its own inherent law, and finally to take low carbon economy development into the track of natural healthy development. Of course, for different socio-economic bodies, as their inherent socio-economic structure and operation mechanism is different, so the path and the time of transition of their low carbon economy development from the exogenous development to the endogenous development are not the same, and the process is often very complex.

From the above analysis it can be found that there are certain interconnected and interdependent features between the exogenous development and the endogenous development. In fact, for any specific socio-economic body, low carbon economy development is a combination of some forms of the exogenous development and the endogenous development. The reason is that, the factors and the powers of economy developments are always limited regardless of the exogenous development or the endogenous development. More importantly, for a specific socio-economic body, the endogenous development comes from internal causes and the exogenous development comes from external causes. The external causes of exogenous development can only through the internal causes of the endogenous development bring into play. At the same time, the internal causes of the endogenous development must in turn gain the support from the external causes of the exogenous development. This is the basic logic of normal operation and evolution of any socio-economic system (Xiangsheng D., 2002). Of course, at different stages of low carbon economy development, the position and importance what they play the role is different. At the initial stage of low carbon economy development, because the internal development factors of specific socio-economic system are limited, it is necessary from the externals to inject the necessary development factors, and thereby the exogenous development is dominant. Once the mechanism of self-development within the specific socio-economic system of low carbon economy has been formed and played a role, then the endogenous development will replace the exogenous development and take a dominant position. However, even in the case that the endogenous development is in dominance, actively to use the external development factors and implement an open development, still help to stimulate the vitality and efficiency of low carbon economy development.

\section{The Dual Governance of the Carbon Source and the Carbon Sink}

The key to low carbon economy development is to take all necessary means, as far as possible to reduce the emissions of greenhouse gases into the atmosphere to minimum or even zero, and thereby to eliminate the greenhouse gas effects that the massive emissions of greenhouse gases cause. This goal may be achieved either from the source of carbon emissions (namely, carbon source) to treat, or by way of timely clearing the carbon dioxide and other greenhouse gases that have produced (This called carbon sink) to treat. The governance from 
the carbon source belongs to a fundamental policy, which can solve the problem of greenhouse gas emissions from the source, so it is an ideal way of low carbon economy development. However, from a practical point of view, to try from the source of greenhouse gas emissions to completely solve the problem of greenhouse gases emissions is almost impossible. As it is related to the technical issues as well as the cost and other socio-economic problems, so even to take the strict measures against low carbon economy development can not still completely solve the problem of greenhouse gas emissions. Therefore, it needs to appropriately take subsequent remedial measures to capture or remove the greenhouse gases that have produced before being released into the atmosphere, so as to achieve the purpose to further reduce or completely remove the greenhouse gas emissions into the atmosphere (S. Vijaya Venkata Ramana et al., 2012). In other words, from the means of development to view, if low carbon economy development wants to gain desired results, it is necessary to take the stereoscopic promotion road of the dual governance of carbon source and carbon sink and the combination of prevention and control. Only by doing so, can the goals and tasks of low carbon economy development be effectively achieved.

According to the Kaya's formula that the "Carbon emissions $=$ Net ratio of carbon emissions in fossil fuels and industries $\times$ Carbon utility intensity $\times$ Inverse of energy conversion efficiency $\times$ Energy utility intensity $\times$ Economic activity" (Toshihiko M. et al., 2006), the factors causing carbon emissions have many aspects including the ratio of carbon emissions, the carbon utility intensity, the energy conversion efficiency, the energy utility intensity, the economic growth and the others in economic activities. However, in the current economic circumstances of China, because the GDP per capita in China is still relatively low, so the increasing of economic scales and the increasing of energy utility intensity caused by the former seem difficult to be avoided. Therefore, the key to reducing carbon emissions is as far as possible to improve the energy use efficiency and to reduce the net ratio of carbon emissions of GDP per unit and the carbon utility intensity, that is, from the carbon source to carry out a governance to reduce greenhouse gas emissions (Howarth R. B., 1997). This is not just the need to reduce greenhouse gas emissions, more importantly it can still promote China's economy transition from extensive growth to intensive growth, so as to fundamentally solve the contradictions of the low efficiency and low quality of economy development.

To improve energy use efficiency and to reduce the net ratio of carbon emissions of GDP per unit are related to all aspects and links of socio-economic activities such as the production, the circulation, the distribution, the consumption and the others. More importantly, the problems of the energy saving and emission reduction appear in both the production and the life side. From the production side to view, because at this stage China's industrialization and informatization are still in the process of accelerated development, wholly the economic structure and the level of economic development have still to be further improved, and the development of certain sectors and industries is still at the stage of extensive growth, so the contradictions of high energy consumption, high emissions and high pollution are still very prominent. In this case, in the production side extensively and deeply to carry out the works of energy conservation and emission reduction is particularly significant. To a certain extent, it directly determines the success or the failure of low carbon economy development. On the other hand, the key that the energy conservation and emission reduction in the areas of production can or not make a good effect is whether the technologies of energy conservation and emission reduction may obtain a major breakthrough. Once the technologies of energy conservation and emission reduction make a major breakthrough, it will fundamentally change the extensive growth pattern of economy. Obviously, in the production side extensively and deeply to carry out the works of energy conservation and emission reduction is not only the needs of low carbon economy development, but also has a crucial role in improving the quality of overall economic development.

From the life side to view, people need to satisfy all basic necessities of the consumption for their own survival and development, but in the consumption it is bound to consume a lot of energy and produce large amounts of garbage. The consumption of energy in the life may at least produce two harmful consequences. On the one hand, in the process of energy use, for example, to use the gas for cooking and heating and so forth, this will produce large amounts of greenhouse gases. On the other hand, the energy production itself such as using the coal combustion for power generation and others will produce large amounts of greenhouse gases, too. At present, the energy consumptions of China's residents have token a rapid upward trend. Furthermore, the growing demand for the consumption of convenience is more and more increasing. In addition, in the period of socio-economic transition because the formation of the values and attitudes of the civilized consumption of people needs still a long process, so the unhealthy phenomenon of blind comparison consumption characterized by the high consumption and the extravagant consumption is in vogue today, which results in the enormous 
waste of energy and resources. The convenient consumption and the unreasonably high consumption not only waste a lot of energy and resources, but also cause a large number of garbage generated, further causing a great deal of pollution on the environment. Therefore, how in whole society to vigorously carry out low carbon action, energetically to cultivate the low carbon life attitudes and lifestyles of the public, actively to promote the low carbon consumption behaviors of civilization and saving, and comprehensively to practice low carbon lifestyle, is another important practical issue that low carbon economy development must address.

Besides improving energy efficiency and reducing the net ratio of carbon emissions of GDP per unit from the production and life side, another important measure from the carbon sources to reduce greenhouse gas emissions is to reduce the carbon utility intensity of GDP per unit, that is, as far as possible to minimize the dependence of socio-economic activities on fossil fuels. Because greenhouse gas emissions are mainly caused by the extensive use of fossil energy, significant reduction in fossil energy use and consumption will be a fundamental solution to greenhouse gas emissions. However, under the current conditions at this stage, to try to completely get rid of dependence on fossil fuels is unrealistic. In this case, on the one hand, it is necessary to accelerate the pace of technological innovation for energy production and utilization and greatly to improve the efficiency of energy production and use, that is, through the economical use of energy to reduce the carbon use intensity of GDP per unit. On the other hand, it is necessary to actively tap and develop renewable and new clean energy, and as far as possible to minimize the dependence of energy on fossil fuels, which can fundamentally solve the issues of the carbon use intensity of GDP per unit. In fact, the renewable and new energy resources in the nature, for example, the solar energy, the wind energy, the hydro energy, the biomass energy, the geothermal energy, the ocean energy, the nuclear power and the others, are very rich, and they are almost inexhaustible energy resources. If these energy resources can be effectively developed and used, it can not only effectively solve the problem of the reduction of greenhouse gas emissions, but also ultimately solve the energy shortage problem. Of course, the development of renewable and new clean energy needs many conditions. Among them, one of the most critical conditions is the ability to achieve a major breakthrough in renewable and new energy technologies, but this can not be accomplished in one move. However, as long as the renewable and new energy technology is unceasingly innovated, it is inevitable that the mankind will eventually rid itself of dependence on fossil fuels.

Of course, if only to try to completely solve the problem of carbon emissions from the carbon source is clearly unrealistic, for no matter how developed the technologies of energy production and use are, it is difficult to achieve zero emissions. Especially under the current conditions at this stage, because the extensive use of fossil fuels is inevitable, it is difficult to fundamentally solve the problem of greenhouse gas emissions, which needs to take an ex-post governance on the greenhouse gases that have been emitted, that is, further through the means of carbon sink to solve the problem of greenhouse gas emissions. The essence of the governance of carbon sinks is carbon neutral, and one of the most main ways is from the carbon source point to capture, sequestrate and utilize the carbon dioxide to cast the carbon dioxide off the atmosphere, so as to mitigate the adverse effects of the carbon dioxide on the climate (Syed Masiur Rahman et al., 2012). Because to capture, sequestrate and utilize the carbon dioxide needs to spend certain costs, so this sort of carbon governance is mainly suited to the relatively concentrated large-scale discharge points such as the thermal power plants, the steel mills, the refineries and so forth. For these relatively concentrated points of large-scale carbon emissions, if we may organically combine the carbon capture, sequestration and utility technologies with other advanced production technologies together, and the large-scale promotion and application is carried out, then it can not only significantly reduce carbon dioxide emissions, but also is conducive to reducing the costs of carbon governance. Because in the future for a long period of time, the petroleum, coal and natural gas will be still China's main sources of energy, and the carbon emissions will also take a further growing trend, so it is necessary to actively create conditions to speed up the pace of the research, development, promotion and application of the carbon capture, sequestration and utilization technologies (Jijun, X. et al., 2010).

Another major way of the governance of the carbon sink is to develop the forest carbon sink projects, that is, through the cultivation and development of forest ecosystems to absorb and remove the carbon dioxide in the atmosphere. Scientific research has proven that the forest is the largest carbon pool in terrestrial ecosystems, it may not only largely absorb the carbon dioxides and the pollutants in the air, but also may release large quantities of oxygen. In addition, the forest has still the functions of conserving water, reducing global surface temperature and the conservation of soil and water (Chunfeng W., 2008). Therefore, energetically to cultivate and develop the forest, and to use the forest to increase carbon sink capacity, are basic low carbon economic measures. The primary task for developing the forest carbon sink projects is vigorously to increase the forest coverage of the territory, and to let all unsuitable for farming or less productive lands (especially the mountains 
and hill slopes) to be greened, which is a systematic and basic work. To this end, on the one hand, it is necessary strictly to prohibit the phenomenon of deforestation and clearing the forest. On the other hand, it is necessary on whole countrywide to deeply carry out persistent afforestation projects, and to strive in a short period of time to make the forest coverage rate in China to reach or exceed the world's average level. Another important mission for developing the forest carbon sink projects is to try to raise the forest coverage rate of cities, for the cities are not only the densely populated settlements for production and life, but also the most concentrated areas of energy consumption and greenhouse gas emissions. Therefore, to establish a comprehensive urban forest eco-system, by way of multi-channels to expand the urban green space, and by the greening to raise the city's carbon sink capacity, not only help to beautify the urban environment, but also have the functions of reducing the city's energy consumption, air pollution and heat island effects, thereby to create a more livable living environment and higher quality of life for the public.

\section{The Low-Carbonization Development of the Industries Based on Technology Innovation}

The basis of low carbon economy development is industrial low-carbonization development, only to realize industrial low-carbonization development it is possible fully to realize the overall low-carbonization development of economy. Because the industrial sectors, especially the sectors of physical industries, are one of the largest areas of resource and energy consumptions, as well as the important sources of the wastes and the greenhouse gas emissions. Especially with the rapid expansion of industrial sectors, what they cause environmental pollution problems will become more and more serious. Even in the developed countries, how to effectively solve the problem of environmental pollution caused by the industrial expansion is a difficult problem, too. For the developing countries, because the extensive economic growth phenomenon has not been still eliminated, the environmental pollution problem caused by the rapid expansion of the industrial sectors is more serious. Therefore, the low-carbonization development of industrial sectors occupies a core place in entire low carbon economy development. And if there is no comprehensive low-carbonization development in industrial sectors, then it is impossible to truly achieve the goals of the energy saving, consumption reduction and emission cut. Just as the low-carbonization development of the industrial sectors occupies a core place in the entire low carbon economy development, so it is the key areas what the future development of low carbon economy will focally resolve (Linhai C., 2009).

At this stage, the basic contradictions what China's industrial development faces are that, on the one hand, China's industrialization and urbanization has not been completed, and thereby the large development of industries is imperative, which will undoubtedly bring the problems of greenhouse gas emissions and environmental pollution. On the other hand, in the existing industries the high energy consumption industries and the high carbon-intensive industries still account for a great proportion, but the existence and development of these industries will aggravate the problems of the greenhouse gas emissions and the environmental pollution caused by the development of whole industries. In this case, the key to promoting the low-carbonization development of industries is on the basis of technical innovation to vigorously adjust and optimize the industrial structure, to encourage and promote the development of low carbon industries, to limit or prohibit the development of high carbon industries, and to comprehensively promote industrial upgrading. Simply speaking, that is, to eliminate backward industries, to transform traditional industries and to cultivate emerging industries.

Because China is still in the process of industrialization and urbanization at this stage, so in whole industrial development the backward industries still account for a very considerable proportion. Especially in some underdeveloped backward areas of economy, the backward industries have even become a main industry. The basic feature of backward industries is the low level of technologies, so they have high energy consumption, low efficiency, high carbon-intensive and high pollution properties. Therefore, how to eliminate backward industries as quickly as possible is one of the problems what the low carbon economy development focally resolves. However, for the certain areas, due to many constraints it is still impossible to completely eliminate the backward industries at this stage. The first problem is how to define the backward industries, for whether an industry is backward industry or advanced industry is relative and dynamic. Some industries compared to developed countries are lagging, but they compared to the domestic other areas are relatively advanced. Some industries at this stage are advanced industries, but in the future they will soon become backward industries. This needs to take a scientific and rational definition on the backward industries. Even though the problem of the definition of backward industries is solved, to try in a short period of time immediately to shut down or merge or switch off all backward industries is also unrealistic, for it will affect the normal development of socio-economy in specific regions. Therefore, to solve the problem of backward industries is not an easy task, and it is necessary on the basis of real economic situation and following the laws of economic development to 
comprehensively use the legal, economic and administrative means to gradually and orderly solve it. It must be noted that, in the context of economic globalization, in order to achieve the goals of low carbon economy development, the developed countries often transfer their backward industries of some high energy consumption and high carbon-intensiveness on a large scale to developing countries. Therefore, it is necessary to raise the threshold of foreign industrial entry to prevent the backward industries into the domestic (Jianqiang B. et al., 2008). For some backward regions, besides guarding against the entry of foreign backward industries, it is necessary to pay attention to prevent the transfer of the backward industries of the domestic developed regions to the developing regions, too.

Compared to the elimination of the backward industries, the task of transforming traditional industries is even more daunting. Because at this stage the traditional industries are still the main bodies of industrial and economic development, it is not only directly related to the people's life, but also has broad market space. However, the main problems that the traditional industries have are relatively backward of the production technologies, craft and equipment, thereby to a certain extent relying on the low level of production and a lot of resources and energy consumption to maintain. At the same time, the re-industrialization strategies that the developed countries are implementing greatly improve the level of production technologies and the international competitiveness of traditional industries, which poses a grave challenge to the development of China's traditional industries. Therefore, it is necessary to fully use the high-tech and the advanced applicable technologies to transform and upgrade China's traditional industries, and through the informatization to boost the industrialization development to enhance the innovation capability and the international competitiveness of China's traditional industries, and thereby to achieve the optimization and upgrading of industrial structure and the development by leaps and bounds of social productivity. The transformation of traditional industries is related to many issues, but its core focuses on two aspects. On the one hand, it is necessary to focus on the energy saving and consumption reduction and the environmental protection to upgrade the informatization level of traditional industries, so as to use it as a breakthrough point to promote the technological upgrading of traditional industries and the upgrading and substitution of their products, to significantly improve the capability of independent innovation of traditional industries, the capability of the added value of products and the comprehensive utilization ratio of resources, laying the foundations for sustainable development. On the other hand, as in the traditional industries the manufacturing industries occupy a basic position, so it is necessary to make great efforts to improve material and technical equipment level of manufacturing sectors, especially the automatization, intelligence and informatization level of manufacturing equipments, so as to enhance the production efficiency, product quality, energy saving and consumption reduction, environmental protection level of the manufacturing and whole traditional industries (Xinhua News Agency, 2011).

In the current situation that the science and technology in the world is increasingly developed, the various types of new and developing industries are emerging. The emerging knowledge and technology-intensive industries taking the information, communication, traffic and transportation as the representative, and the emerging green industries represented by the new energy, the new materials, the energy saving and environmental protection and the modern service industries, have the features and advantages of low energy consumption, low pollution, high industrial linkage and long value chain, and they represent the direction and trend of future global economic development. Therefore, how to foster these strategic emerging industries has become the strategic focus of national competition and development. The significance that vigorously promotes the development of emerging industries is that, it not only can directly drive the optimization and upgrading of industrial structure, but also lay a material and technological foundation for the transformation and upgrading of traditional industries. Especially, the development of knowledge and technology-intensive emerging industries such as the information, communication, traffic and transportation and so forth, will create favorable conditions for the transformation and development of the automatization, intelligence and informatization of traditional industries. More importantly, the development of emerging industries, especially the development of strategic emerging industries, will inevitably hasten the emergence of a large number of high-tech and new technologies, again by them to drive the development of key technologies, core technologies and common technologies of industries, which lays a foundation for overall upgrading of whole industrial technologies. Obviously, to make great efforts to cultivate and develop the emerging industries for industrial low-carbonization development is essential. It may be said that, if there is no the development of emerging industries, the industrial low-carbonization development can not make substantive progress and effectiveness.

Of course, both the transformation of traditional industries and the cultivation of emerging industries are built on the basis of technological innovation. If there is no technological innovation, their development will lose the 
basis and conditions. Therefore, the key to whether or not the industrial low-carbonization development based on the optimization and upgrading of industrial structure can make a success is whether a significant progress in technological innovation can be made. From the perspective of industrial low-carbonization development, in addition to speeding up the pace of the innovation of the information technologies, the advanced manufacturing and major equipment technologies and other key technologies, the focus of current efforts is to develop, promote and apply the cleaner production technologies that are focused on the energy saving and consumption reduction and the environmental protection. As compared to the developed countries, the current energy and resource use intensity of a considerable part of China's domestic industries is still high, and the energy consumption and the emission pollution are more serious. Therefore, the potentials of the energy saving, consumption reduction and emission cut for China are very great, too. At the same time, the clean production technologies belong to the technologies of applicability, a large number of clean production technologies have now entered a matured stage of the standardization of applications, thereby easily to be promoted and applied. Therefore, relatively speaking, the marginal costs of developing, promoting and applying the clean production technologies focusing on the energy saving, consumption reduction and environmental protection are relatively low, and it is one of the most effective ways to rapidly promote the industrial low-carbonization development in a short period of time (Can, W., Ke, W., 2008).

The low-carbonization development of industries is a complex socio-economic system engineering involving a wide range. Therefore, only under the guidance, support and promotion of the government, can a success be made. The role of the government on industrial low-carbonization development is firstly overall planning and demonstration. Because the essence of industrial low-carbonization development is to realize the strategic adjustment and the comprehensive optimization and upgrading of industrial structure, so it is related to the country's strategic development planning and the construction of the relevant laws and regulations. At present, China has drown up the national programs and the mediate-and-long-term emission reduction targets to address the climate change, and has early or late introduced a series of laws and regulations such as the Cleaner Production Promotion Law, the Renewable Energy Act, the Circular Economy Promotion Law and so forth. However, the specific measures for development are not still perfect, and it is still necessary to work out the implementation details of having a more practical operability, so as to standardize and guide the deeper and wider development of industrial low-carbonization. At the same time, the government must also make the preferential policies on the tax, the investment and financing and the others to encourage and promote micro-economic entities consciously to take part in the practice of industrial low-carbonization development, for whether the industrial low-carbonization development can make a success ultimately depends on the economic behaviors of micro-economic entities. In addition, the government can also promote the low-carbonization development of industries and economies by way of enforcing the system such as the technology standards of the energy saving and emission reduction and the environmental protection, the energy efficiency labels, the carbon footprint assessments and the low carbon product certification, the green certificates, the contract energy management, the procurement of the government's energy saving and so forth.

\section{The Low-Carbonization Development of Energy Based on Technology Innovation}

The core of low carbon economy development is to realize the goals of the energy saving, consumption reduction and emission cut. Therefore, how to realize the low-carbonization development of energy is one of the most critical issues what low carbon economy development needs to resolve, for the low-carbonization development of energy is not only an inevitable requirement of the energy saving, consumption reduction and emission cut, but also constitutes one of the basic contents of the low-carbonization development of industries. More importantly, whether can or not achieve low-carbonization development is still related to the issue of a country's energy safety, which not only affects the real socio-economic development, but also decides whether the national strategic goals of the future socio-economic development can be achieved or not, and at the same time whether the comprehensive development capabilities of nation can be effectively enhanced or not. Obviously, the low-carbonization development of energy is not just an inevitable requirement of low carbon economy development, but also in fact it has already constituted an important integral part of a country's socio-economic development strategy. Therefore, its role on the future socio-economic development will become increasingly prominent.

From the aspect of its contents to view, the low-carbonization development of energy includes two basic aspects of the low-carbonization of energy use and the low-carbonization of energy development. Among them, the low-carbonization of energy use lies in a core position, for it directly determines the energy saving, consumption reduction and emission cut. One of the most important issues of the low-carbonization of energy use is how to 
improve energy use efficiency to fundamentally solve the problem of energy consumption reduction. Compared to the developed countries, the current energy use efficiency in china is relatively low, and thereby the potentials of the energy saving, consumption reduction and emission cut are very much great. Therefore, if a major breakthrough can be made on the aspects of the energy efficiency improvement, it will help to greatly reduce the energy consumption and ease the contradiction of energy crisis (Howarth, R. B., 1997). To improve the energy use efficiency and as far as possible to reduce the energy consumption in production and daily life of people, are related to many aspects, for example, the energy saving of the production, building, traffic and transportation, everyday life and so forth, which is a complex system engineering that is closely related to many aspects including the society, economy, technology and others. The key to reducing the energy consumption is low carbon technological innovation. It is possible to achieve the goal with less energy consumptions to get more outputs through low carbon technological innovation. Especially, the innovation and application of micro-energy technologies will achieve a revolutionary change on the reduction of energy consumption. However, the low carbon technology innovation is inevitably restricted by many constraints. At least in a short period of time, the degree of technical change is limited. Therefore, another key link to reducing energy consumption is as far as possible to reduce energy waste and maximally to realize the recycling use of energy resources from the use and management aspects of energy, that is, to develop the recycling economy.

Another important measure of the low-carbonization development of energy use is to minimize the use of fossil energy as far as possible and to realize the conversion of energy utilization structure. With the continued economic growth, it will undoubtedly result in the increasing growth of energy consumption. However, the fossil energy in real energy structure still accounts for an absolute proportion. Because the fossil energy is high-carbon energy, the ratio of its carbon emissions and its pollution levels are higher. Therefore, in the case that total energy use is growing, if we can effectively reduce the proportion of fossil fuels in energy use, it is inevitably conducive to reducing the carbon emission intensity of economic development. This needs to vigorously promote the conversion of energy use structure. The structural transformation of energy use involves many fields of production and life of people. Its core is that, on the one hand, it is as far as possible to use natural energy (including biomass energy), for example, in the building and housing to use the natural ventilation, natural lighting and others, which is one of the most effective ways of energy-saving and emission reduction. On the other hand, it is as far as possible to use the new energy such as the solar energy, wind energy and others. Different from traditional fossil fuels, the new energy is not only low carbon energy, but also belongs to renewable energy, and thereby it is inexhaustible. In fact, in the construction, the traffic and transportation and the daily life of people, the potentials of the structural transformation of energy use are enormous. At present, the emerging green industries represented by the green and intelligent buildings and the new energy vehicles, are making a global rapid development in an ascendant trend. With the continuous development of these emerging green industries, it will essentially promote the transition of energy use structure from the traditional high-carbon energy represented by fossil energy to low-carbon energy taking new energy and renewable energy as the representative.

However, the potentials of low-carbonization development of energy use are limited after all. With the continuous improvement of the material and cultural and the living standards of people, the demand of socio-economic development for energy will continue to grow, too. On the one hand, it will increase the treatment costs of energy saving, consumption reduction and emission cut. On the other hand, it will still produce the problem of energy security and safety, which is thereby increasing the costs of energy production and utilization. Therefore, it is necessary from energy use links to promote the low-carbonization development of energy, as well as from energy-self production process to find the ways of governance to promote the low-carbonization development of energy, that is, to achieve the low-carbonization of energy development, and both are mutual complementary. The low-carbonization of energy development includes two aspects. On the one hand, it is necessary through technological innovation to change the traditional mode of the production of fossil fuels, for example, to substitute the coal-fired electricity production for the gas-fired generation to improve the efficiency of energy resource use, with the minimal consumption of energy resources to produce more electricity, and so forth. This is the problem that needs be urgently addressed firstly in energy development. On the other hand, it is necessary as quickly as possible to change the single energy structure mainly dominated by the fossil fuels at this stage, actively to develop new energy, and comprehensively to realize the diversification of energy and the optimization of energy structure based on the diversification. In a long run, it is the fundamental way of the low-carbonization development of energy and ensuring energy safety. Therefore, how to realize the diversification of energy and the optimization of energy structure is the strategic focus of the low-carbonization 
development of future energy.

In a general sense, the key to realizing the diversification of energy and the optimization of energy structure is how to efficiently develop new energy. Different from traditional fossil fuels, the new energy and renewable energy represented by the hydro energy, nuclear energy, solar energy, wind energy, biomass energy, geothermal energy, ocean energy and others, is a non-fossil energy. It is not only inexhaustible, but also low carbon, clean, and environmentally friendly, and thereby helps to guarantee the energy supply as well as greatly to reduce the greenhouse gas emissions. Therefore, the development and utilization of new and renewable energy, has not only become an important content of the low-carbonization development of energy, but also become an important measure that all countries in the world achieve the strategy of energy safety (Muhammad Shafiq Siraj, 2012). From a practical point of view, although the development and utilization potentials of new and renewable energy are huge, yet at this stage the proportion that they take in the total energy production and use is still very small, providing a golden opportunity for the development of energy diversification in the future. At present, the main factors restricting the development and utilization of new and renewable energy are that, compared to the traditional fossil fuels, the production costs of new and renewable energy are higher. Therefore, even though the new and renewable energy has the technical feasibility of production, yet it lacks real economic feasibility due to high production costs, thereby making it difficult to be effectively developed. Therefore, it needs the government to adopt the relevant regulations and policy measures to encourage, support and promote. At the same time, with the continued technology innovation and the large-sized production of new and renewable energy, the production costs of new and renewable energy will continue to decline, so eventually it will become an important emerging energy industry. When the time comes, it can not only achieve the strategy targets of the low-carbonization development of energy and the national energy security, but also as an emerging industry it will become an new and important economic growth point of national economic development.

Whether it is the low-carbonization of energy use or the low-carbonization of energy development, the basis and the key are technological innovation (Hourcade, J. C., Crassous, R., 2008). From the technological innovation strategy of developed countries to view, almost all countries have elevated the low carbon energy technology innovation (especially the technology innovation of new energy and renewable energy) to the height of national strategy, for the low carbon energy technology innovation is not only related to the issues of national energy security and energy safety, but also related to the cultivation and development of new energy and renewable energy industries in the future. From the future trend of economic and technical development to view, the new energy and renewable energy industries will undoubtedly become strategic emerging industries, and thereby it will play a very important role on promoting socio-economic development and improving national comprehensive competitive. However, from a technical perspective to view, at this stage the low carbon energy technologies are still at the preliminary stage of development, and the technology gap between the domestic and the abroad is not very obvious. Furthermore, in the partial technology fields such as the use of solar and wind power, the new energy vehicles and so forth, China has gone in the forefront of the world, which creates extremely favorable conditions for low carbon energy technology innovation in China. The key to the issue is that, how China should grasp this opportunity to take the leader position in achieving significant innovation and breakthrough in the fields of low carbon energy technologies, thereby obtaining a dominant position in the development of the strategic emerging industries of new energy and renewable energy. To this end, it is necessary to take the low carbon energy technology innovation as the focus of national science and technology research, and expectedly to achieve a major breakthrough in the basic technology research concerned, so as to lay the foundation for the innovation of applied technologies. At the same time, the government should actively encourage and support enterprises and social institutions to carry out the applied low-carbon energy technology innovation, so as to form an integrative low-carbon energy technology innovation system of the organic combination of the government and the enterprises (Jiahai Y. et al., 2011).

\section{Conclusion}

Whether the selection of low carbon economy development road is or not correct, is directly related to whether the goals of low carbon economy development can be smoothly and effectively realized. This paper comprehensively and systematically demonstrates the economic connotation of the choice of low carbon economy development road from different perspectives such as the development pattern, the development strategy, the development path, the motive force for development, the development means, the development priorities and so forth. This research reveals that, in the particular context at this stage, the low carbon economy development in China must take such a development road, for example, the combination of the government-led and the market-oriented operation, the combination of the overall gradual and the partial rapid development, the 
combination of the balanced development in a long term and the unbalanced development in a short term, the combination of the exogenous development and the endogenous development, the dual governance of the carbon source and the carbon sink, as well as the industry low-carbonization development and the energy low-carbonization development based on low carbon technology innovation. Therefore, it is complex socio-economic system engineering.

At present, the world economy is being in the decline phase of economic cycle. If trying to completely reverse this situation, it is necessary to change the traditional road and pattern of economic development, and actively seek a new road and pattern of development. To this end, the developed countries universally implement the development strategy of re-industrialization and the development strategy of promoting the upgrading and transformation of traditional industries at the same time, actively culturing and developing the strategic emerging industries taking the green industries such as the new energy, the new materials, the modern services, the energy saving and environmental protection and the others as representatives, which gives rise to an upsurge in global low carbon economy development. Therefore, that what road of low carbon economy development is selected, is not only directly related to whether the strategic transformation of China's economy from the traditional high-carbon economy to a new low-carbon economy can successfully be achieved, but also directly determines whether the China in the game of the world's low carbon can obtain a dominant position. The analysis of this paper indicates that, it is necessary from a broader perspective to explore the issue of low carbon economy development road. Only by doing so, can we deeply understand and grasp the theory essence of low carbon economy development road and its economic connotations, and thereby lay out a clear roadmap for low carbon economy development, so as to provide a scientific theory basis for the policy formulation and practice of low carbon economy development.

Certainly, the choice theories and economic contents of low carbon economy development road are very rich. Because of its importance, it is necessary to further explore it in the future. Especially, the low-carbon technology stragety, the carbon emission right trading system and scheme, and the carbon finance need be profoundly and systematically researched further. In addition, with the low carbon economy development and the availability of its data, more empirical analysis needs be done, too.

\section{Acknowledgments}

This study was sponsored by the National Social Science Foundation of China (Grand Number: 10XJY004). We appreciate the generous support from the funds.

\section{References}

Bartelmus, P. (2008). Quantitative Eco-nomics: How Sustainable are Our Economies? New York, NY: Springer-Verlag New York Inc. http://dx.doi.org/10.1007/978-1-4020-6966-6

Climate Change and Low Carbon Economic Research Institute of the Renmin University of China (CCLCERIRUC). (2010). Low Carbon Economy_China Tell the Copenhagen through Actions (pp.59-61). Beijing: Petroleum Industry Press.

Can, W., \& Ke, W. (2008). By technological innovation to promote low carbon economy development. In Kunmin, Z., Jiahua, P., \& Dapeng, C. (Eds.), On the Low Carbon Economy (pp. 418-434). Beijing: China Environmental Science Press.

Chunfeng, W. (2008). Forestry options under low carbon economy. In Kunmin, Z., Jiahua, P., \& Dapeng, C. (Eds.), On the Low Carbon Economy (pp. 411-417). Beijing: China Environmental Science Press.

Ellerman, A. D. (2002). Designing a tradable permit system to control of $\mathrm{SO}_{2}$ emissions in China: principles and practice. The Energy Journal, 24(3), 1-26.

Guiyang, Z. (2005). Path and potential analysis of China low carbon development. Pacific Journal, 11, 79-87.

Hourcade, J. C., \& Crassous, R. (2008). Low-carbon societies: A challenging transition for an attractive future. Climate Policy, 8, 607-612. http://dx.doi.org/10.3763/cpol.2008.0566

Howarth, R. B. (1997). Energy efficiency and economic growth. Contemporary Economic Policy, 15, 1-9. http://dx.doi.org/10.1111/j.1465-7287.1997.tb00484.x

Jiahai, Y., Junjie, K., Cong, Y., \& Zhaoguang, H. (2011). Energy conservation and emissions reduction in China-progress and prospective. Renewable and Sustainable Energy Reviews, 15, 4334-4347. http://dx.doi.org/10.1016/j.rser.2011.07.117 
Jiahua, P. (2009). How to develop low carbon economy of China. Green Leaf, 5, 21-27.

Jianqiang, B., Yang, M., \& Feng, C. (2008). Low carbon economy: new change of human economic development way. Chinese Industrial Economy, 4, 153-160.

Jijun, X., Huang, D., \& Gang, Z. (2010). Low Carbon Economy Report (pp. 43-63). Beijing: Electronics Industry Press.

Junfeng, L., \& LingJuan, M. (2008). Low carbon economy is new rules to regulate world development. In: Kunmin, Z., Jiahua, P., \& Dapeng, C. (Eds.), On the Low Carbon Economy (pp. 178-186). Beijing: China Environmental Science Press.

Karen Fisher-Vanden. (2003). The effects of market reforms on structural change: implications for energy use and carbon emissions in China. The Energy Journal, 24, 27-62. http://dx.doi.org/10.5547/ISSN0195-6574-EJ-Vol24-No3-2

Linhai, C. (2009). Low Carbon Economy: The Green Revolution and Big Pattern of Global Innovation Competition (pp. 163-226). Beijing: Economic Science Press.

Lovins, A. B. (1977). Soft Energy Paths: Toward A Durable Peace. Harmondsworth, UK: Penguin Books.

Muhammad Shafiq Siraj. (2012). Energy resources-The ultimate solution. Renewable and Sustainable Energy Reviews, 16, 1971-1976. http://dx.doi.org/10.1016/j.rser.2012.01.030

Strachan, N., Foxon, T., \& Fujino, J. (2008). Modelling long-term scenarios for low-carbon societies. Climate Policy, 8, 601-611. http://dx.doi.org/10.3763/cpol.2008.0538

Syed Masiur Rahman, A. N. (2012). Khondaker. Mitigation measures to reduce greenhouse gas emissions and enhance carbon capture and storage in Saudi Arabia. Renewable and Sustainable Energy Reviews, 16, 2446-2460. http://dx.doi.org/10.1016/j.rser.2011.12.003

The British Government. (2003). Our energy future: creating a low carbon economy. London, UK: UK Energy White Paper 2003.

Toshihiko, M., Tatsuya, H., Saeko, H., \& Mikiko, K. (2006). Assessment of $\mathrm{CO}_{2}$ reductions and economic impacts considering energy-saving investments. The Energy Journal, 24, 175-283.

Uwe, R., \& Markus, B. (2008). Global perspective to achieve a low-carbon society (LCS): Scenario analysis with the ETSAP-TIAM model. Climate Policy, 8, 60-75. http://dx.doi.org/10.3763/cpol.2007.0493

Vijaya, V. R., S., Iniyanb, S., \& Ranko, G. (2012). A review of climate change, mitigation and adaptation. Renewable and Sustainable Energy Reviews, 16, 878-897. http://dx.doi.org/10.1016/j.rser.2011.09.009

Xiangsheng, D. (2002). On the mode of economic growth. Finance Research, 3, 9-13.

Xiangsheng, D., Shasha, L., \& Jing, W. (2013). Ecological strategy of city sustainable development. APCBEES Procedia, 5, 410-415 (in press).

Xiangsheng, D., Meijuan L., \& Hongfei, W. (2013). Innovation Strategy of Low Carbon Technology in China: Technology for Market. International Journal of Enviromental Science and Development, 4, 233-238.

Xinhua News Agency. (2011). The 12th Five-Year Plan for China's National Economic and Social Development of the People's Republic (2011-03-16). Beijing: Xinhua News Agency.

Yao, W. (2010). Carbon Finance-Global Perspective and Chinese Layout (pp. 40-55). Beijing: China Economic Press.

Yong, J., \& Jakob, de S. A. (2009). Resources Energy Environment Social-Science Engineering Principles of the Cycle of Economy (pp. 121-175). Beijing: Chemical Industry Press.

Zhijun, F. (2009). Some thoughts of low carbon economy. China Soft Science, 12, 18-23.

\section{Copyrights}

Copyright for this article is retained by the author(s), with first publication rights granted to the journal.

This is an open-access article distributed under the terms and conditions of the Creative Commons Attribution license (http://creativecommons.org/licenses/by/3.0/). 